\title{
Progressive care orientation: Incorporating a program that supports transition to practice
}

\author{
La Donna Y. Christy, Jo-Anne A. Senneff \\ Center for Nursing Research, Education and Practice, Houston Methodist Hospital, Houston, Texas, USA
}

Received: September 27, 2018

Accepted: March 5, 2019

Online Published: August 21, 2019

DOI: $10.5430 /$ jnep.v9n12p19

URL: https://doi.org/10.5430/jnep.v9n12p19

\begin{abstract}
Objective: Progressive care units (PCUs), also sometimes called intermediate care units, improve the utilization of beds within intensive care units while adjusting the workload of the nurse. PCUs encompass a scope of care between the critically ill patient and the acute care patient. Owing to the advanced skills set needed, nurses with limited experience in this setting may benefit from an orientation course in addition to on-the-job training. The purpose of this project was to develop and evaluate an orientation program for nurses working in progressive care settings at a multi-site hospital system.

Methods: Kolb's experiential learning theory and adult learning theory were used as a framework to plan and design a 2-day instructional program that addressed the cognitive, psychomotor, and affective aspects of learning needs.

Results: A total of 244 participants completed the 2-day program. The teaching strategies were shown to be effective, as indicated by survey results reporting a mean score of 4.36 on a 1-5 Likert scale (with a score of 1 indicating the presenter did not clearly articulate the subject and 5 indicating that the presenter clearly articulated the subject). The participants stated that they intended to make changes in practice and identified changes to improve the program (e.g., inclusion of high-fidelity manikins, patient-controlled anesthesia).

Conclusions: Incorporating a specialized training program for newly licensed nurses and nurses transitioning to the PCU with less than 2 years' experience in this setting may improve the nurse's confidence and performance of patient care skills in this highly acute environment.
\end{abstract}

Key Words: Nursing orientation, Acute care nursing, Adult learning, Progressive care

\section{INTRODUCTION}

The care of critically ill patients has evolved over the past 2 decades since the admission guidelines for intensive care and progressive care were introduced by the American College of Critical Care Medicine in 1998 and 1999, respectively. ${ }^{[1,2]}$ The established intensive care environment shifted to a multimodal environment encompassing both patients who were critically ill and patients who were progressively ill. These 2 scopes of care, while both requiring close monitoring, can be safely separated into units that provide 2 different aspects of specialized care. Progressive care is a broad term that can in- clude the following types of patient care units: intermediate, step-down, telemetry, and transitional care. ${ }^{[3]}$ Progressive care patient acuity may not necessitate an intensive care unit (ICU) setting, but may also not be appropriate for a medical-surgical setting. ${ }^{[4,5]}$ Progressive care units (PCUs), also sometimes called intermediate care units, improve the utilization of ICU beds while adjusting the workload of the nurse. ${ }^{[6]}$

The American Association for Critical Care Nurses (AACN) discussed the guidelines set forth by the American College of Critical Care Medicine and emphasized the need for spe-

\footnotetext{
* Correspondence: La Donna Y. Christy; Email: lychristy@ houstonmethodist.org; Address: Center for Nursing Research, Education and Practice, Houston Methodist Hospital, Houston, Texas, USA.
} 
cialized training for nurses working in the progressive care setting. ${ }^{[4]}$ In our hospital system, which has a large academic medical center and six community hospitals around the city, training for progressive care nurses was solely the responsibility of the preceptor, resulting in an inconsistent process for training nurses in progressive care. A progressive care orientation program, combining the unit-based orientation of the preceptor with a course didactic component and handson skills session, was developed for nurses in this setting to improve confidence and performance of patient care skills needed in the population and well as improve consistency in training across all hospitals in the system. This was a new course for the system; previous orientation strategies for bedside nurses working in a PCU included working alongside a preceptor with no formalized class instruction.

The purpose of this project was to design and evaluate a progressive care course that would enrich the current orientation model of sole preceptor-based unit orientation. The program was developed and lead by the main hospital's critical care nursing educators, with the assistance of an interdisciplinary team (pharmacists, respiratory therapists, nurse practitioners and clinical nurse specialists). This program assisted in responding to common knowledge gaps that the progressive care nurse may experience when working in this setting. The three main aims of this project were:

- To provide a standardized course mandatory for all newly licensed nurses and current practicing nurses working in progressive care areas.

- To increase knowledge of nurses working in progressive care units by providing a program integrating learning domains.

- To provide a safe environment in which to learn disease-specific attributes of the progressive care patient population while developing critical thinking skills.

\subsection{Andragogy}

Adult learning has evolved over the course of the 21 st century. In fast-paced critically-ill patient care settings, nurse clinical educators (NCEs) must conceptually identify appropriate learning strategies to ensure that practitioners have the most up-to-date evidence to safely care for patients. Providing an enriched orientation for learners who have some clinical experience, or even limited experience in a new clinical setting, can be a challenge, especially in an environment that requires critical thinking and application of higher-level skills sets. Andragogy, a theoretical underpinning that identifies how adults learn, asserts 6 principles: ${ }^{[7]}$

(1) The need to know - adults must identify why they are learning (or relearning) a concept.
(2) Motivation - adults have internal and external motivators that create the desire to learn.

(3) Readiness - adults see a need to learn when learning is relevant to their environment.

(4) Experience - experience sets the foundation for learning activities in the adult learner; adults learn from experience and experiential learning to develop associations in the classroom environment.

(5) Self-concept - adults are responsible for their own choices.

(6) Orientation - the adult learner's goals are situation oriented. In addition to these principles of adult learning, a majority learning in adulthood comes from the individual's experiences (see Figure 1). ${ }^{[8,9]}$

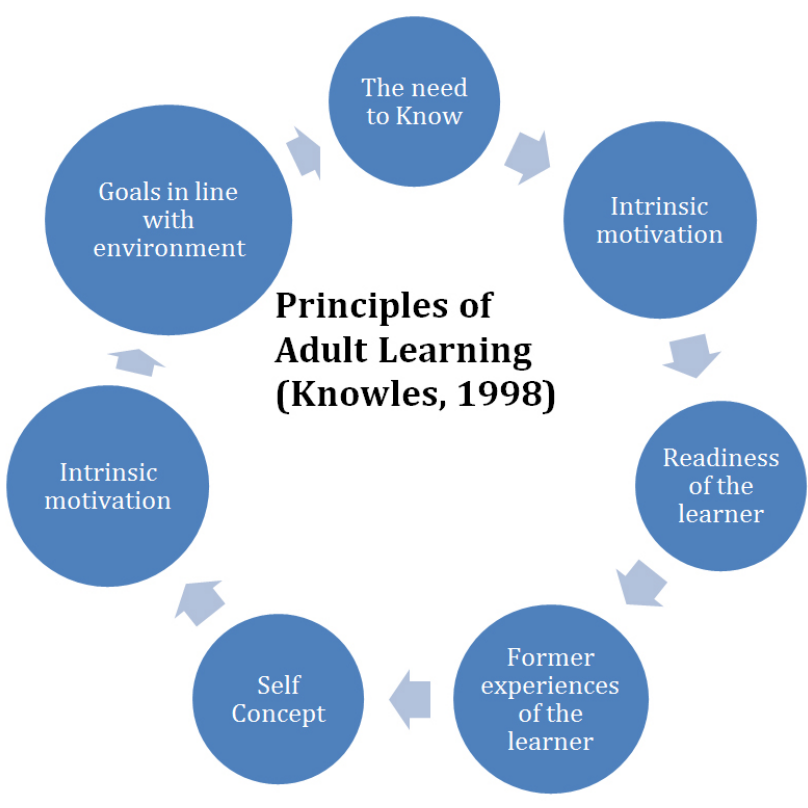

Figure 1. Adult Learning Theory

\subsection{Kolb Experiential learning}

In contrast to children, adults primarily learn through their experiences. Kolb defined learning as an experiential process based on self-efficacy (one's commitment and internal self-ability to participate in and draw from a learning experience). ${ }^{[10]}$ Kolb maintains that there are 4 learning styles that each identify a different method of instruction: diverging, assimilating, converging, and accommodating (see Table 1). ${ }^{[11]}$

The divergent learner learns by assimilating ideas and may learn best through case scenarios. The assimilator learns by integrating the knowledge presented and mentally organizing the information in a common-sense method. The converging learner is a problem solver and focuses on task learning. This learner may also benefit from simulation activities as 
well as hands-on demonstration skills. The accommodating combination of didactic, case scenario, group discussion, and learner learns through applied demonstration within a group. hands-on skills stations.

In all learner styles, learning may be reinforced by using a

Table 1. Kolb learning styles*

\begin{tabular}{ll}
\hline Learning Styles & Learning Preferences \\
\hline Diverging learners & - Learn best through concrete experience and reflective observation \\
& - Learners prefer to work in groups and participate in generating ideas \\
Assimilating learners & - Learn best through reflective observation and abstract conceptualization \\
& - Learners are most interested in abstract concepts and can put information in a concise logical format \\
Converging learners & - Learn best through abstract conceptualization and active experimentation \\
Accommodating learners & - Learners are problem solvers who prefer technical tasks to social issues \\
\hline
\end{tabular}

*Adapted from Kolb and Kolb (2009) and Manolis et al. (2013). ${ }^{[10,11]}$

Studies suggest that using a combination of learning principles coupled with the experiential learning method may be a suitable strategy when planning for adult learners. ${ }^{[7,8]}$ Appropriately structured educational programs that integrate cognitive, affective, and psychomotor approaches will increase the likelihood of success in clinical practice. ${ }^{[12]}$ If all facets of learning are addressed, the adult learner is more likely to retain the information.

Adults learn through teaching and instructional models that address common learning styles (seeing, hearing, doing, thinking, and knowing). ${ }^{[13]}$ These methods address the student's knowledge, skills, and abilities (the original concepts in Bloom's taxonomy that address the cognitive, affective and psychomotor aspects of adult learning). ${ }^{[14]}$ A revision of the taxonomy emphasizes 6 hierarchical stages of adult learning (see Figure 2): remembering, understanding, applying, analyzing, evaluating, and creating, ${ }^{[15,16]}$ so, instruction for adult learners with different levels of expertise in this setting would include a combination of learning approaches (classroom presentation and didactic, hands-on demonstration/return demonstration of common skills seen in the progressive care clinical areas, and critical thinking group work designed to enhance critical thinking and skills acquisition in patient care modalities). To integrate the learning theories within the planning of the course, simulation activities were also an important consideration.

Simulation activities (such as learning skills stations, handson demonstration, and return demonstration) prove to have a positive effect on learners as opposed to a traditional classroom setting in which the focus is on strictly presentation. ${ }^{[17]}$ Adults learn through practice and repetition (i.e., the combined cognitive, affective and psychomotor experience); furthermore, adults require education that is relevant to the practice to be meaningful. ${ }^{[18]}$ Developing programs in a 1000+ hospital bed academic medical center can be challenging in that the education should truly reflect the learner's specific needs to be meaningful to their practice but should be tailored to address the care needs of the specialized unit.

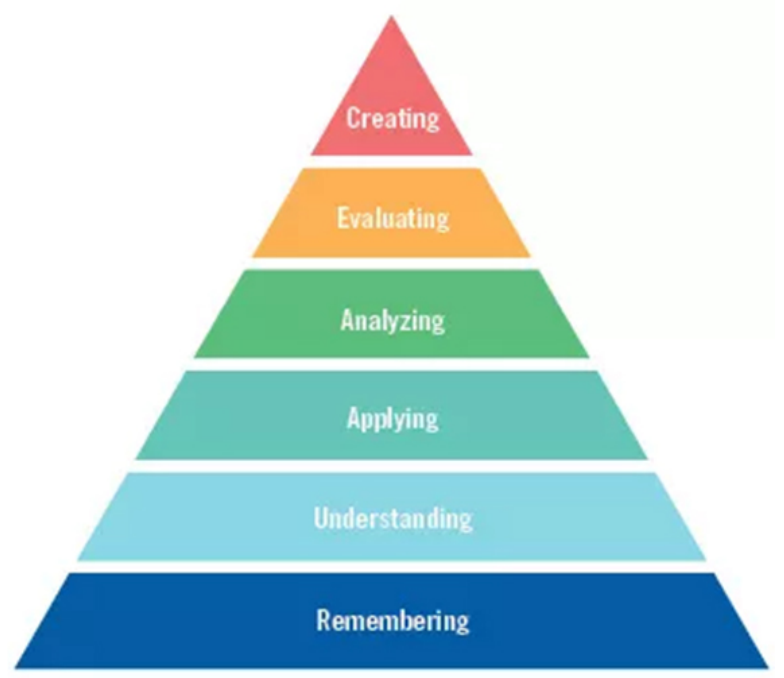

Figure 2. Bloom's Taxonomy Adapted from Vanderbilt University Center for Teaching

Literature suggest that educational requirements for working in a progressive care setting include knowledge and skills acquisition of cardiac monitoring and lead placement, continuous intravenous infusion administration, pre- and postprocedure monitoring, noninvasive/invasive hemodynamics interpretation and interventions, identifying and responding to blood gas interpretation, advanced airways, parental nutrition, and equipment orientation and use. ${ }^{[5]}$ Current hospital policies are in development for the progressive care areas; limited recommendations exist in this setting surrounding 
training and orientation to provide safe and effective care within the organization.

\subsection{Gap analysis of progressive care units}

A formal needs assessment to identify gaps in practice knowledge was completed by sending an electronic survey to nurses who worked in the progressive care setting. Data were obtained from an ongoing survey in the nurse residency program for newly licensed nurses of the skills and disorders they felt needed more time for instruction and hands-on experience. Leadership in these areas also completed the survey and identified several gaps in practice. Nurses who worked in PCUs stated the need for a class on medication management, right atrial pressure/central venous pressure monitoring, how to manage arterial lines, and advanced airway management. The newly licensed nurses identified the need for practice of the following skills: tracheostomy care, use of a selfinflating resuscitator, oxygen delivery devices, code blue management and roles in a code, chest tubes, and central venous catheter/arterial lines maintenance. A focus group using nominal technique was also organized with the leadership team that managed the PCUs; the group identified similar needs and added the need for incorporating critical thinking in the program. The nurse residency coordinators identified opportunities through formal and informal feedback from the newly licensed nurse that there was a strong need for specialized training when selected to work in specific environments (to include the progressive care setting). Collaboration with the nurse residency coordinators and experts in the environment identified a need for more robust skills and knowledge acquisition in the higher acuity environment.

A progressive care orientation program was thus developed and implemented to fit the needs of nurses in orientation in the progressive care area, where there was no previous specialized training, that is, where training was "on the job." The management and nurse residency coordinators agreed the program would be beneficial for addressing the educational needs in this population of nurses.

\section{MethodS}

\subsection{Application of learning theory}

Kolb's experiential learning theory and principles of adult learning were used as the framework for developing an integrated program that incorporated Bloom's taxonomy (cognitive, psychomotor, and affective learning strategies). ${ }^{[10]}$ Each topic of instruction would incorporate a presentation, an evolving case study, and a skills station that had an additional case study. The skills station component of the course addressed the following: indications and rationale for the skill, supply/equipment list needed for the skill, troubleshoot- ing associated with equipment and supplies, demonstration of how to perform the skill, discussion and learned experiences of the learners, and return demonstration of each learner performing the skill.

\subsection{Participants}

The learners who participated in the progressive care orientation program included newly licensed nurses who worked in a PCU, or ICU within the community hospitals in our system, and nurses who worked within the main hospital and who had less than 2 years' experience in a PCU. Newly licensed nurses who worked in the ICUs in the community setting were included in the progressive care orientation program because of the similarities between the ICU environment and the progressive care environment in the community hospitals in the system. Nurses who worked in medical-surgical settings were excluded. Nurses who worked at the main campus in critical care areas were also excluded; a critical care orientation program already existed for nurses working in the ICUs.

\subsection{Program implementation}

A 16-hour program, given over two days, was designed for the learners. To address the learning gaps and ensure enough time for participation in the skills station, each topic was identified for its level of difficulty and provided a time frame based on the number of participants. The planning team identified a need to incorporate skills and activities that included a teaching component, a hands-on component, and an opportunity for return demonstration and discussion. The team agreed that 1 day would not be an adequate amount of time to address the common learning needs as identified in the needs assessment. Two 8-hour days was a sufficient amount of time to address the didactic components and provide a robust hands-on experience for learning.

The 2-day program was held quarterly from September 2016 to March 2018. The program included interactive presentations that required the learners to review and evaluate evolving case studies and work as a group to critically think through patient care scenarios. Skills stations were also provided to solidify the didactic portion, translating instruction into skills and critical thinking. Each presentation lasted 1 hour; to engage the learner, the skills stations were placed strategically between 2 lecture presentations to incorporate different learning styles.

To ensure learning consistency in didactic and skills topics, day 1 of the program included cardiovascular, circulatory, and high-acuity medication management. Topics addressed were hemodynamics, waveforms and troubleshooting, pressure bag setup, cardiac rhythms, vasopressor/anxiolytic in- 
fusions, insulin, and diabetic ketoacidosis management. A formative summary of learning needs was assessed by using an introductory question session with the use of audience polling devices so that participants could answer questions anonymously. Between topics a skills station was set up and participants were required to manage waveforms, set up a pressure bag and perform arterial catheter monitoring, set up intravenous pumps and program infusions, manage a patient who was clinically deteriorating and perform a mega code, properly operate a defibrillator, and work through complex patient scenarios in small groups. The participants were placed in small groups of 3 to 5 (depending on the class size) and rotated as a group through each of the stations. Each station took approximately 30 to 45 minutes (at a maximum) to complete.

Day 2 of the course included airway management concepts and skills that coincided with the respiratory system. This was a topic of importance identified by the leadership team, the nurses working in the PCUs, and the newly licensed nurse. The team agreed there was a need to spend a considerable amount of time on the respiratory portion of the course. Topics covered in day 2 of the course consisted of advanced airways, long-term ventilator management, bilevel positive airway pressure (BiPAP) management, tracheostomy care, chest tubes and long-term chest drain management, and pacemaker concepts and troubleshooting. Again, skills stations were placed strategically for the benefit of each learning style. Participants were given the opportunity for hands-on demonstration of tracheostomy care and proper suctioning, identifying pacemaker rhythms with the use of high-fidelity simulation monitors, troubleshooting and management of a chest tube and chest tube leaks (with the use of a lung apparatus that simulated bubbling in the water seal chamber), and an integrated scenario that included blood gas interpretation and escalation of care/ventilator management.

The program speakers were interprofessional. Topics were presented by subject matter experts. The respiratory component, ventilator management, BiPAP, and blood gas topics were taught by the respiratory care department; the medication components were presented by each of the critical care pharmacists housed in the various ICUs; the critical care educators participated in the skills stations and provided the lecture component for hemodynamics and pacemakers.

\subsection{Data collection}

After the program was completed, a post-orientation survey was sent to the participants via email. The post-orientation survey included questions about content, presentation style, and intent to make a change in practice. Questions included rating the expertise of the presenter, efficacy of teaching methods, intent to change practice, the learner's additional learning needs, and suggestions to improve the activity (see Table 2). Surveys were electronic and anonymous. Data was analyzed using IBM SPSS Statistics for Windows, Version 25.0 (Armonk, NY: IBM Corp). Mean scores were used to aggregate quantitative responses to the questionnaire. Themes were identified and grouped according to skills/presentation needs (see Table 3 ).

Table 2. Post-orientation survey questionnaire*

\begin{tabular}{|c|c|}
\hline Post-Orientation Survey Question & Answer Options \\
\hline Rate the expertise/effectiveness of each individual presenter. & $1=$ poor, 2 = fair, 3 = good, 4 = very good, $5=$ excellent \\
\hline The teaching methods/learner engagement strategies were effective. & $\begin{array}{l}1 \text { = strongly disagree, } 2=\text { disagree, } 3=\text { good, } 4=\text { agree, } 5 \\
=\text { strongly agree }\end{array}$ \\
\hline $\begin{array}{l}\text { As a result of this activity, do you intend to make any changes to your } \\
\text { professional practice/performance? }\end{array}$ & Yes/No \\
\hline $\begin{array}{l}\text { Based on today's activity, please list additional learning needs that you } \\
\text { might have. }\end{array}$ & Open-ended comments section \\
\hline Please offer any suggestions you may have for improving this activity. & Open-ended comments section \\
\hline
\end{tabular}

*Source: Harper and Maloney (2016) and Walker and Stevenson (2016). ${ }^{[19,20]}$

\section{RESUlts}

A total of 244 participants completed the 2-day program; only 61 post-program surveys were completed. This may be due to majority of nurses who attended the program were newly licensed nurses. Contact hour for re-licensure requirements do not apply for the newly licensed nurse renewing for the first time. ${ }^{[21]}$ The pre-orientation question session identified that $50 \%$ to $65 \%$ of the participants had minimal knowledge

Published by Sciedu Press of hemodynamics and titratable medications associated with working in a PCU. On a Likert scale of 1 to 5, the follow-up survey revealed that the presenters' teaching methods were ranked with a mean of 4.36 out of 5 (with a score of 1 indicating the presenter did not clearly articulate the subject and 5 indicating that the presenter clearly articulated the subject). Survey questions included "rate the effectiveness of each presenter" and "the teaching methods/learner engagement 
strategies were effective" (see Figure 3). The mean average of both questions from all participants' responses again ranged from 4.3 to 4.5 , respectively. The participants said that they felt they were more competent to care for patients with various diagnoses after completing the program.

A summary of themes can be found in Table 3. Themes from the open-ended comments question, "Based on today's activity, please list any additional learning needs you might have" included: medication review for oral, disorder-based simulation scenario, and how to effectively communicate to the licensed practitioner. Suggestions for improving the course consistently identified the need for a robust scenario using a high-fidelity manikin and/or a standardized patient.

Table 3. Identified themes of post-survey results

\begin{tabular}{ll}
\hline Summary of themes identified in the post survey questionnaire \\
\hline & Skill \\
& - Patient controlled analgesia setup and Troubleshooting \\
Based on today's activity, please list & - SBAR review and how to address the advanced practitioner/provider(Situation, \\
additional learning needs that you might & Background, Assessment, Recommendations) \\
have. & - Unit in-service on monitoring equipment \\
& - Medication review during unit in-services on oral anticoagulants and guidelines, \\
& cardiac medications \\
& Presentations \\
& - Presentations should build up to a simulation scenario \\
Please offer any suggestions you may have & Hands on learning during presentation(simultaneously) \\
for improving this activity. & - Need simulation environment with a manikin \\
& - Need to incorporate simulation onto the mega code \\
& - Have an actor/actress act out a patient scenario (standardized patient)
\end{tabular}

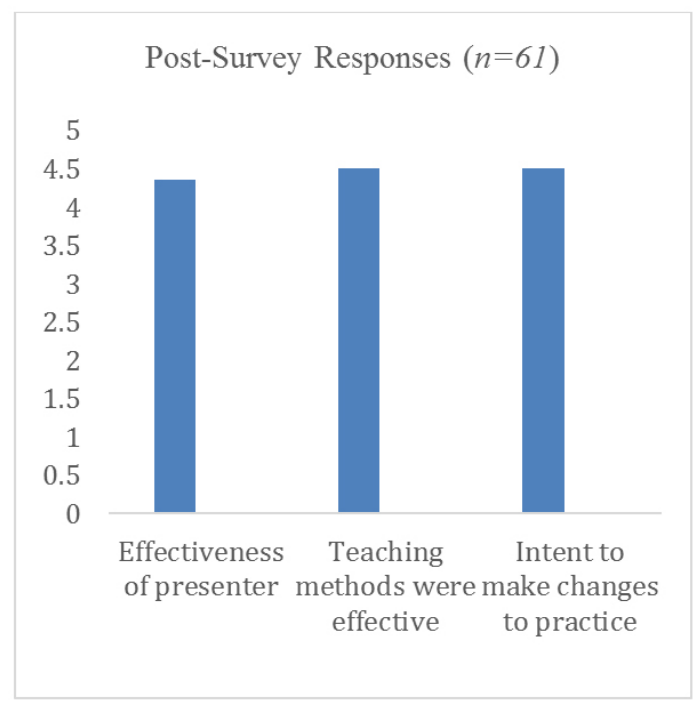

Figure 3. Survey Response of questionnaire items

\section{Discussion}

The goal of this project was to create a standardized class that addressed knowledge gaps of nurses working in PCUs. The course was initially piloted and tailored for newly licensed nurses and new nurses working in this environment with no prior experience. This course allowed bedside nurses an opportunity to increase their knowledge and experience in a safe learning environment. The participants were able to participate in integrated learning and to put the concepts learned into simulation of skills. This type of environment promotes a positive experience as the time to develop skills with actual patients is shorter. ${ }^{[22]}$ Each aim was assessed for its success or failure.

Aim 1: To provide a standardized course mandatory for all newly licensed nurses and current practicing nurses working in progressive care areas. The first aim of the project was met as this program is currently mandatory for all newly licensed nurses who work in PCUs in all hospitals in the system. The class has since been opened to any nurse working in a PCU setting within the hospital system. The course has also been written into the guidelines for the nurse residency program, which obtained its national recertification status since the inception of the class.

Aim 2: To increase knowledge of nurses working in progressive care units by providing a program integrating learning domains. The second aim of his project is in progress. The surveys reported that learning had occurred and there was an intent to change practice, but there was no initial follow-up of the nurses on the units at 3,6,9, and 12 months to identify a change in practice (as evidenced by skill demonstration, review of charts, leadership discussion). Kirkpatrick's four 
levels of evaluation affirm that while learning typically occurs after an activity, behavior is evaluated during job performance, and results may take months to years to observe. ${ }^{[23]}$ Even though the survey reported positive feedback, the number of completed surveys was low, so inferences could not be made. The initial group is currently rounding on units and meeting with leadership to determine additional needs for the course and current practice of the staff who attended the course.

Aim 3: To provide a safe environment in which to learn disease-specific attributes of the progressive care patient population while developing critical thinking skills. The third aim was met; the participants were provided a safe, nonthreatening learning environment and were given the opportunity to ask questions and discuss best practice, while using their critical thinking skills to formulate answers for the case studies. As a result of the initial 2-day course, the leadership team agreed to filter employees with less than 2 years of experience to the class a small number at a time to accommodate and maintain staffing ratios. The nurse residency coordinators planned the course in conjunction with the residency program and made the program a mandatory requirement for all graduate nurses working in this setting (including the newly licensed nurses working in the community hospitals).

There were several limitations to this project. The low number of survey responses in relation to the total number of attendees made it difficult to truly quantify most of the learner's perceptions of the course. Because the PCU can be very specialized or take the form of a medical-surgical unit that cares for various highly acute patients, PCUs across health care organizations vary. ${ }^{[24]}$ Several units were identified as transitional care units but were not typically staffed for highly acute conditions. Two units that identified as intermediate care units operated like an ICU and flexed from a 1:3 to a 1:2 patient ratio as the needs of the patient dictated. Another challenge was the leadership's request to reduce the number of days in the course to a 1-day program. The rationale from the leadership team was the time constraint for orientation related to staffing ratios. The course specifics were discussed during a follow-up session with the leadership team, and the rationale associated with the 2-day program, and the leadership team agreed 2 days were needed.

The participants stated a need to have more simulation, incor- porating changing patient conditions and complex patient scenarios to include shock, high-fidelity simulation, and rhythm interpretation. A formal post-test was not given; the pretest was a generalized theme of concepts provided by the introductory questions collected by using the electronic polling devices. As a result of the follow-up surveys of the class, full simulation will now be integrated into the class for each participant. With the initial 2-day program, simulation manikins were not available. Future class sessions will incorporate high-fidelity simulation topics, such as code blue scenarios encompassing medication titrations. Intubation and code management will be simulated using a high-fidelity manikin and will include an interdisciplinary scenario (with hospital residents, physicians, respiratory therapists and pharmacists).

\section{Implications for practice}

PCUs will continue to be the needed bridge between the medical-surgical unit and the ICU. Creating a program for experienced/limited experienced nurse learners must always start with a sound, detailed needs assessment to identify gaps in practice and get the nurses point of view of what he or she needs (as well as reviewing trends in data, metrics, and ongoing dissuasion with the leadership team). Incorporating a specialized training program that augments the unit-based orientation with a preceptor for newly licensed nurses and for nurses transitioning to the PCU with less than 2 years' experience in a progressive care/critical care setting may improve nurses' confidence and competence, ultimately affecting patient outcomes. Adding a course available to all nurses in the progressive care areas may also help bridge learning gaps of nurses currently working in these areas. An integrated approach to learning that incorporates knowledge, skills, and abilities can increase comprehension and may improve skills acquisition. Interprofessional collaboration made this project successful. Future efforts will include identifying critical care intensivists to provide education from the physician's perspective.

\section{ACKNOWLEDGEMENTS}

We thank the critical care/progressive care staff for their collaborating efforts in this project.

\section{CONFlicts of InTEREST Disclosure}

The authors declare that there is no conflict of interest.

\section{REFERENCES}

[1] Nasraway SA, Cohen IL, Dennis RC, et al. Guidelines on admission and discharge for adult intermediate care units. Crit Care Med. 1998; 26(3): 607-610. PMid:9504593 https://doi.org/10.1097/00

\section{6-199803000-00039}

[2] Egol A, Fromm R, Guntupalli KK, et al. Guidelines for intensive care unit admission, discharge, and triage. Task Force of the American College of Critical Care Medicine, Society of Critical Care 
Medicine. Crit Care Med. 1999; 27(3): 633-8. PMid:10199547 https://doi.org/10.1097/00003246-199903000-00048

[3] Plate JDJ, Leenen LPH, Houwert M, et al. Utilisation of intermediate care units: a systematic review. Crit Care Res Pract. 2017; 2017: 1-10 PMid:28775898 https://doi .org/10.1155/2017/8038460

[4] AACN. Progressive Care Fact Sheet [Internet]. American Association of Critical-Care Nurses; c2008 [cited August 24, 2018].

[5] Stacy KM. Progressive care units: different but the same. Crit Care Nurse. 2011; 31(3): 77-83. PMid:21632595 https ://doi .org/10 $.4037 /$ ccn2011644

[6] Solberg BC, Dirksen CD, Nieman FH, et al. Introducing an integrated intermediate care unit improves ICU utilization: a prospective intervention study. BMC Anesthesiol. 2014; 14: 76. PMid:25276092 https://doi.org/10.1186/1471-2253-14-76

[7] Taylor DC, Hamdy H. Adult learning theories: implications for learning and teaching in medical education: AMEE Guide No. 83. Med Teach. 2013; 35(11): e1561-e1572. PMid:24004029 https: //doi.org/10.3109/0142159X.2013.828153

[8] Bonesso S, Gerli F, Pizzi C. The interplay between experiential and traditional learning for competency development. Front Psychol. 2015; 6: 1305. https://doi.org/10.3389/fpsyg. 2015 .01305

[9] Knowles MS. The Modern Practice of Adult Education: From Pedagogy to Andragogy. New York: Association Press; 1988.

[10] Kolb AY, Kolb DA. Experiential learning theory: a dynamic, holistic approach to management learning, education and development. In: The SAGE Handbook of Management Learning, Education and Development. 2009; April: 42-68. https://doi.org/10.4135/ 9780857021038.n3

[11] Manolis C, Burns DJ, Assudani R, et al. Assessing experiential learning styles: a methodological reconstruction and validation of the Kolb Learning Style Inventory. Learn Individ Differ. 2013; 23(1): 44-52. https://doi.org/10.1016/j.lindif . 2012.10.009

[12] Weigel FK, Bonica M. An active learning approach to Bloom's taxonomy: 2 games, 2 classrooms, 2 methods. US Army Med Dep J. 2014 Jan-Mar; 21-9.

[13] Dunn R, Griggs S. Learning Styles and the Nursing Profession. New York: National League for Nursing; 1998.
[14] Anderson LW, Krathwohl DR. A Taxonomy for Learning, Teaching and Assessing: A revision of Bloom's taxonomy of educational objectives. New York: Longman; 2001.

[15] Krau SD. Creating educational objectives for patient education using the new Bloom's Taxonomy. Nurs Clin North Am. 2011; 46(3): 299 312. PMid:21791265 https://doi.org/10.1016/j . cnur. 201 1.05 .002

[16] Su WM, Osisek PJ. The Revised Bloom's Taxonomy: implications for educating nurses. J Contin Educ Nurs. 2011; 42(7): 321-327. PMid:21707023 https://doi.org/10.3928/00220124-20110 621-05

[17] Cant RP, Cooper SJ. Simulation-based learning in nurse education: systematic review. J Adv Nurs. 2010; 66(1): 3-15. PMid:20423432 https://doi.org/10.1111/j.1365-2648.2009.05240.x

[18] Shrivastava SR, Shrivastava S. Employing adult learning theories in designing a module. Res Dev Med Educ. 2017; 6(2): 64-65. https://doi.org/10.15171/rdme.2017.014

[19] Harper MG, Maloney P, eds. Overview of nursing professional development. J Nurses Prof Dev. 2016; 32(4): 228-230. PMid:27434326 https://doi.org/10.1097/NND.0000000000000270

[20] Walker M, Stevenson G. Learning theory support of simulation to improve nurses' care of critically ill patients. J Contin Educ Nurs. 2016; 47(1): 27-31. PMid:26790494 https://doi .org/10.392 8/00220124-20151230-08

[21] Texas Board of Nursing. (2018, December 5). Texas Board of Nursing. Available from: Texas Board of Nursing: https://www. bon. texas.gov/education_continuing_education.asp

[22] Berragan L. Simulation: an effective pedagogical approach for nursing? Nurse Educ Today. 2011; 31(7): 660-663. PMid:21334797 https://doi.org/10.1016/j.nedt.2011.01.019

[23] Jeffery AD, Longo MA, Nienaber A. Staff Educator's Guide to Professional Development. Indianapolis: Sigma Theta Tau International; 2016.

[24] Wendlandt B, Bice T, Carson S, et al. Intermediate care units: a survey of organization practices across the United States [published online February 11, 2018]. J Intensive Care Med. PMid:29431046 https://doi.org/10.1177/0885066618758627 